\title{
Genetic analysis of hydatidiform moles in paraffin wax embedded tissue using rapid, sequence specific PCR-based HLA class II typing
}

\author{
A C Bateman, S K Hemmatpour, J M Theaker, W M Howell
}

\begin{abstract}
Aims-To determine the applicability of rapid, sequence specific polymerase chain reaction (PCR)-based HLA class II genotyping for the distinction of complete from partial hydatidiform moles (HM) using DNA extracted from formalin fixed and paraffin wax embedded tissue.

Methods-Nine HM were studied. DNA was extracted from formalin fixed and paraffin wax embedded tissue after mechanical separation of decidual and molar components. HLA class II DRB (DRB1, $-3,-4$, and -5 ) and DQB1 genotyping was performed using a parallel series of PCR reactions, each of which contained sequence specific primers designed to amplify different HLA DRB and DQB1 alleles or allele groups (PCR-SSP analysis). In each case the HLA DRB and DQB1 genotypes identified within the decidua and $H M$ were compared.
\end{abstract}

Results-Within the decidual tissue, HLA DRB genotypes were assignable in all nine cases, and HLA DQB1 genotypes were identified in seven cases. Within the molar tissue, HLA DRB genotypes were assignable in seven cases, and at least one HLA DQB1 allele was identified in seven cases. Interpretation based on HLA class II genotyping was therefore possible in two cases classified on histological appearances as complete $H M$, in four classified as partial $H M$, and in one $H M$ of uncertain type. Different HLA DRB and DQB1 haplotypes were identified within the decidual and molar tissue from both complete HM, consistent with a solely paternal origin and supporting the histological diagnosis. HLA DRB and DQB1 alleles common to the decidual and molar tissue were present within the four partial HM and the HM of histologically uncertain type, consistent with combined maternal and paternal genetic input to these $H M$, supporting the histological diagnosis in four cases and suggesting that the histologically equivocal case was also a partial HM.

Conclusion-PCR-SSP HLA class II DRB and DQB1 typing is reliably applicable to DNA extracted from formalin fixed and paraffin wax embedded tissue. Therefore, in a suitably equipped HLA typing laboratory, this technique provides a useful adjunct to histological examination for differentiation of complete from partial HM.

(F Clin Pathol 1997;50:288-293)

Keywords: hydatidiform mole; HLA class II typing; tissue typing; polymerase chain reaction

The incidence of hydatidiform moles (HM) has been estimated at between 0.5 and 2.5 per 1000 pregnancies. ${ }^{1}$ Distinction between complete and partial HM is important because complete HM are associated with a significantly higher risk of progression to persistent trophoblastic disease than the partial form. Fukunaga et al calculated an $18 \%$ risk of progression for complete and a $0 \%$ risk for partial $\mathrm{HM},{ }^{2}$ while Paradinas et al found that $28 \%$ of their patients with complete HM required chemotherapy compared with $3 \%$ of those with partial HM. ${ }^{3}$ Although all patients with HM undergo serial serum human gonadotrophin level estimation, those with complete HM may require more rigorous follow up. Distinction between complete and partial HM may be difficult on histological grounds, a problem exacerbated by a recent trend towards early evacuation of HM before characteristic features of complete HM, such as widespread hydropic change within villi, have developed. ${ }^{3}$

Karyotyping has demonstrated that complete HM are usually diploid but contain only paternal genetic material, derived from ovum fertilisation either by two spermatozoa (dispermy) or by one spermatozoa which subsequently undergoes chromosomal reduplication (monospermy). ${ }^{4}$ Conversely, partial HM are most often triploid, containing one set of maternal genes together with two sets from the father. ${ }^{5}$ Karyotyping can, therefore, provide useful information regarding the genetic constitution of HM but its usefulness may be limited by the absence of suitable markers with which to assign maternal or paternal origin to molar chromosomes. ${ }^{6}$ Flow cytometry has been used as an adjunct to the classification of HM, based on the difference in DNA ploidy observed within complete and partial $\mathrm{HM}^{2}$ The ploidy of both forms may vary ${ }^{7}$; therefore, information obtained from flow cytometric analysis of some HM may be noncontributory.

The entirely paternal origin of complete HM has prompted evaluation of microsatellite pattern analysis in DNA extracted from molar tissue as an aid to the distinction of complete
Alexandra Hospital, Cosham

Portsmouth PO6 3LY,

Accepted for publication 22 January 1997 
Table 1 Associations of DRB1 alleles with the DRB3, -4 , and -5 genes $^{22}$

\begin{tabular}{ll}
\hline DRB3, -4 and -5 genes & Associated DRB1 alleles \\
\hline DRB3 (52) & $11,12,13,14,17$ \\
DRB4 (53) & $04,07,09$ \\
DRB5 (51) & 15,16 \\
No DRB3, -4 or -5 & $01,08,10$ \\
$\quad$ association & \\
\hline
\end{tabular}

from partial HM. A variety of techniques has been used including restriction fragment length polymorphism analysis, ${ }^{9}$ with or without initial DNA amplification using the polymerase chain reaction (PCR), ${ }^{10}$ and direct identification of microsatellite polymorphisms using PCR primers flanking hypervariable regions of DNA. ${ }^{11-13}$

A recently described related but alternative approach to the distinction of complete from partial HM uses a comparison of the HLA genotypes of the molar and maternal tissues. This technique may be of value in laboratories where HLA typing is performed routinely meaning such methods are readily available. The HLA genes are the most polymorphic loci within the human genome and so they are ideally suited to the study of individual identity ${ }^{14}$ and parentage. Owing to the wholly paternal origin of genetic material within complete HM, one or two sets of paternal HLA alleles, but no maternal HLA alleles, should be detectable within DNA extracted from a complete HM. Conversely, at least one maternal set of HLA alleles should be detectable within DNA derived from a partial HM. Identification of HLA alleles does not require gene transcription so it can be performed using DNA extracted from cells that do not express HLA class II antigens. Linkage disequilibrium occurring between individual HLA class II DRB and DQB1 alleles provides an internal control as each HLA DRB1 allele is most commonly associated with certain HLA DQB1 alleles and with one of the HLA DRB3, -4 , or -5 genes (encoding the DR52, 53, and 51 specificities, respectively) (table 1). ${ }^{16-19}$

One previous study used PCR amplification of DNA extracted from fresh molar tissue and parental peripheral blood leucocytes, followed by HLA allele identification using sequence specific oligonucleotide probing (PCR-SSOP typing) in seven cases of HM, and concluded that PCR-based HLA genotyping was a useful adjunct to histological classification. ${ }^{6}$ However, this study was limited to analysis of the DRB1 gene and therefore the extra information and internal controls potentially provided by analysis of further HLA loci such as the DRB3, -4 , -5 , and DQB1 genes was not available. In addition, the published method required high quality DNA extracted from fresh or frozen material.

We have developed a PCR-SSOP typing method applicable to the degraded DNA extractable from formalin fixed and paraffin wax embedded material. ${ }^{14}{ }^{20}$ More recently, we adapted a rapid, sequence specific primerbased method (PCR-SSP) for a similar purpose. ${ }^{15}$ We have used these methods in ret- rospective HLA disease association studies ${ }^{20}$ and for surgical biopsy identification. ${ }^{21}$ In the present study, we investigated the applicability of this rapid PCR-SSP method for the genetic analysis of a series of HM, to demonstrate the usefulness of this approach, as applied to DNA derived from formalin fixed molar and decidual biopsy tissue.

PCR-SSP typing was used to compare the HLA DRB and DQB1 genotypes of the molar and maternal (as assessed from the decidua) tissue in nine cases of HM. In some cases only a very small amount of intact DNA was extractable, and required initial PCR amplification of the entire second exon within the DRB1 gene before successful "second round" PCR-SSP analysis could be achieved ("nested" PCR-SSP"1).

\section{Methods}

Nine cases of HM were retrieved from the files of the histopathology department at Southampton General Hospital. Cases classified locally as partial HM had undergone routine histological review at Charing Cross Hospital, London, where one case originally diagnosed as partial $\mathrm{HM}$ was re-classified as complete. Eight HM had been thus classified on morphological criteria as follows: complete, three cases; partial, five cases; HM of uncertain type, one case. In each case, representative formalin fixed and paraffin wax embedded tissue blocks were selected and the decidual tissue was mechanically separated from the molar tissue. In most instances, separation of these tissues was achieved through melting down the paraffin wax blocks and individually re-embedding the decidual and molar tissue. After DNA extraction, most cases underwent HLA DRB (DRB1 $,-3,-4$, and -5) and DQB1 typing using "direct" PCR-SSP analysis. In a minority of cases, where DNA yield was low, HLA DRB typing was achieved using "nested" PCR-SSP typing.

\section{DNA EXTRACTION}

Five $20 \mu \mathrm{m}$ paraffin sections were cut from each block. Following dewaxing, DNA was extracted using overnight proteinase $\mathrm{K}$ digestion, as described previously. ${ }^{20}$ DNA concentration and integrity was estimated by running a $2 \mu \mathrm{l}$ aliquot on a $1 \%$ agarose gel.

Immediately before and following removal of the five $20 \mu \mathrm{m}$ sections from each paraffin wax block, a $5 \mu \mathrm{m}$ section was cut and stained with haematoxylin and eosin. These stained sections underwent histological examination to assess the presence and degree of cross contamination between the mechanically separated decidual and molar tissues.

DIRECT PCR-SSP HLA DRB AND DQB TYPING PCR amplification was performed using panels of primers specific to different hypervariable sequence motifs within the (second) exons of the HLA class II DRB1 and DQB1 genes. All primer sequences were derived from the literature, ${ }^{22-24}$ or were designed in house, using published DRB 1 allele sequences. ${ }^{25}$ Sequences were combined into 23 mixes for DRB typing, 
detecting $19 \mathrm{DRB}$ alleles (or groups of alleles) plus the presence of the DRB3, -4 , or -5 genes (encoding the DR52, 53, and 51 specificities, respectively). Eight primer mixes for DQB typing were employed, detecting eight DQB1 alleles (or groups of alleles). The details of the PCR mixes and conditions have been described previously. ${ }^{15}$ PCR products were visualised by running the entire reaction mix on a $2 \%$ agarose gel (Sigma, Dorset), prestained with ethidium bromide (Sigma, $0.5 \mathrm{mg} / \mathrm{ml}$ gel), at $100 \mathrm{~V}$ for 20 minutes, in $1 \times$ TAE buffer (40 $\mathrm{mM}$ Tris base, $5.7 \%$ glacial acetic acid, $50 \mathrm{mM}$ EDTA, $\mathrm{pH}$ 8.0). Gels were viewed and photographed under ultraviolet transillumination.

NESTED PCR-SSP HLA DRB TYPING

PCR amplification of the second (variable) exon of the HLA DRB1, -3, -4, and -5 genes was performed using PCR primers and amplification conditions as described for the 11 th International Histocompatibility Workshop, ${ }^{27}$ and as routinely used for PCR-SSOP HLA class II typing for disease association studies in our laboratory, ${ }^{20}$ with minor modifications. The details of the PCR mixes and conditions for both amplification steps have been described previously. ${ }^{21}$ PCR products were visualised by running the entire reaction mix on a $2 \%$ agarose gel.

\section{Results}

HLA class II DRB and DQB1 alleles were identifiable using direct PCR-SSP typing in 15 of the 18 DNA samples. Three cases which were untypable using direct PCR-SSP analysis, and 11 cases requiring further confirmation of the HLA DRB genotype, underwent nested PCR-SSP DRB typing. The results are shown in table 2.

Histological examination of the sections cut immediately before and after removal of the $20 \mu \mathrm{m}$ sections for DNA extraction revealed that extensive $(>30 \%)$ cross contamination had occurred only in the sample of decidual tissue from case 9. Minimal $(<10 \%)$ cross contamination was also present in the histo-

Table $2 H L A D R B$ and $D Q B 1$ alleles detected in the nine cases of hydatidiform mole (HM) studied

\begin{tabular}{|c|c|c|c|c|c|}
\hline \multirow[b]{2}{*}{ Case } & \multirow{2}{*}{$\begin{array}{l}\text { Histological } \\
\text { diagnosis }\end{array}$} & \multirow[b]{2}{*}{ Tissue } & \multicolumn{3}{|l|}{$H L A$ class II type } \\
\hline & & & $D R B 1$ gene & $D R B 3,-4,-5$ genes & $D Q B 1$ gene \\
\hline \multirow[t]{2}{*}{1} & Complete HM & D & 01,15 & $51(5)$ & 05,06 \\
\hline & & $\mathbf{M}$ & 14,07 & $52(3), 53(4)$ & $02, \star \star$ \\
\hline \multirow[t]{2}{*}{2} & Complete HM & D & 04,04 & $53(4)$ & 08,08 \\
\hline & & $\mathbf{M}$ & 13,04 & $52(3), 53(4)$ & 06,02 \\
\hline 3 & Complete HM & $\begin{array}{l}\mathrm{D} \\
M^{\star}\end{array}$ & 15,04 & $51(5), 53(4)$ & $\star$ \\
\hline \multirow[t]{2}{*}{4} & Partial HM & $\mathrm{D}$ & 15,04 & $51(5), 53(4)$ & 06,08 \\
\hline & & $M$ & 15,0301 & $51(5), 52(3)$ & 06,02 \\
\hline \multirow[t]{2}{*}{5} & Partial HM & $\mathrm{D}$ & 0301,14 & $52(3)$ & 02,05 \\
\hline & & $M$ & $0301,04,1302$ & $52(3), 53(4)$ & 02,06 \\
\hline \multirow[t]{2}{*}{6} & Partial HM & $\mathrm{D}$ & 01,04 & $51(5), 53(4)$ & 05,07 \\
\hline & & $M$ & 01,04 & $51(5), 53(4)$ & $05,07,08$ \\
\hline \multirow[t]{2}{*}{7} & Partial HM & $\mathrm{D}$ & 15,04 & $51(5), 53(4)$ & 06,07 \\
\hline & & $\mathrm{M}$ & $15,04,07$ & $51(5), 53(4)$ & $02, \star \star$ \\
\hline 8 & Partial HM & $\begin{array}{l}\mathrm{D} \\
M^{\star}\end{array}$ & 01,04 & $53(4)$ & 05,08 \\
\hline \multirow[t]{2}{*}{9} & HM ?type & $\mathrm{D}$ & 15,12 & $51(5), 52(3)$ & $\star$ \\
\hline & & $M$ & 15,12 & $51(5), 52(3)$ & $07, \star$ \\
\hline
\end{tabular}

$\mathrm{D}$, decidual tissue; $\mathrm{M}$, molar tissue. ${ }^{\star}$ HLA alleles not assignable. logical sections related to five further DNA samples.

In case 1 , the HLA DRB1 and DQB1 alleles detected within the molar tissue (DRB1 14 , 07 ; DR52, 53; DQB ${ }^{\star} 02$ ) were entirely different from those detected in the decidual tissue (DRB1*01，15; DR51; DQB1*05，06). A second DQB1 allele was not detected within the molar tissue although the observed $\mathrm{DRB} 1{ }^{\star} 14$ allele would most commonly be associated with a DQB ${ }^{\star} 05$ allele. ${ }^{16}$ These results indicate a solely paternal genetic origin for the molar tissue, and the two different DRB1 alleles detected within the molar sample suggest a dispermic mechanism of fertilisation.

In case 2 , the molar tissue was typed as DRB1*13，04; DR52，53; DQB1*06, 02. Apparent homozygosity for the DRB1 and DQB1 loci $\left(\mathrm{DRB} 1{ }^{\star} 04,04\right.$; DR53; DQB1 ${ }^{\star} 08$, $08)$ in the decidual tissue was confirmed after repeated typings in which a second DRB1 or DQB1 allele was not detected (fig 1). A $\mathrm{DRB} 1{ }^{\star} 04$ allele was detected within both the decidual and molar tissue. However, within the decidua the $\mathrm{DRB} 1^{\star} 04$ allele was associated with a $\mathrm{DQB} 1^{\star} 08$ allele while in the molar tissue the DRB $1^{\star} 04$ allele was associated with a DQB $1{ }^{\star} 02$ allele. The linkage between the latter two alleles is rare but has been reported previously. ${ }^{19}$ Therefore, these two DRB1*04 alleles are most likely to have been derived from different individuals. These results strongly suggest a solely paternal genetic origin for the molar tissue, and the two different DRB1 and DQB1 alleles detected within the molar sample again suggest a dispermic mechanism of fertilisation.

In case 3, the decidual tissue was typable only using nested PCR-SSP analysis which is currently applicable solely to the DRB genes; therefore, no DQB1 type was assignable. The molar tissue in this case was untypable even when nested PCR-SSP analysis was used. ${ }^{22}$

In case 4 , the molar tissue was typed as $\mathrm{DRB}^{\star}{ }^{\star} 15,0301 ; \mathrm{DR} 51,52 ; \mathrm{DQB} 1{ }^{\star} 06,02$ and the decidual tissue was typed as DRB1* 15,04 ; DR51，53; DQB $1{ }^{\star} 06,08$. Therefore, the DRB $1^{\star} 15$ and $\mathrm{DQB} 1{ }^{\star} 06$ alleles were common to the molar and maternal tissue, suggesting that these two alleles within the molar tissue were derived from the maternal genome.

In case 5 , the molar tissue was typed as $\mathrm{DRB}^{\star}{ }^{\star} 0301,04,1302 ; \mathrm{DR} 52,53 ; \mathrm{DQB} 1^{\star} 02$, 06 and the decidual tissue was typed as $\mathrm{DRB} 1{ }^{\star} 0301,14 ; \mathrm{DR} 52 ; \mathrm{DQB} 1{ }^{\star} 02,05$. The $\mathrm{DRB} 1{ }^{\star} 0301$ and $\mathrm{DQB} 1{ }^{\star} 02$ alleles were therefore shared by the maternal and molar tissue, suggesting that these two alleles within the molar tissue were derived from the maternal genome. The three DRB1 alleles detected within the molar sample additionally indicate that this tissue was triploid.

In case 6, the same HLA DRB and DQB1 alleles were detected within the molar and decidual tissue (DRB1*01, 04; DR51, 53; DQB $1^{\star} 05,07$ ). Additionally, a third DQB1 allele $\left(\mathrm{DQB} 1{ }^{\star} 08\right)$ was identified within the molar sample, indicating that this tissue was triploid. The DRB $1^{\star} 01$ and $\mathrm{DQB} 1{ }^{\star} 05$ alleles detected within the molar and decidual tissue 

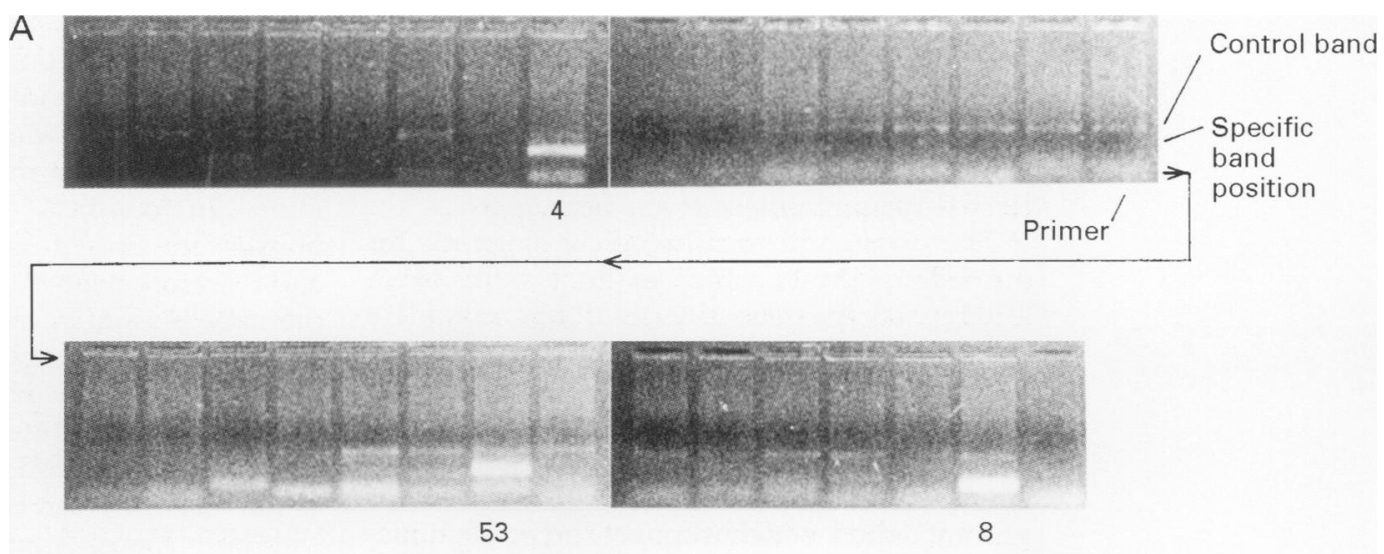

B

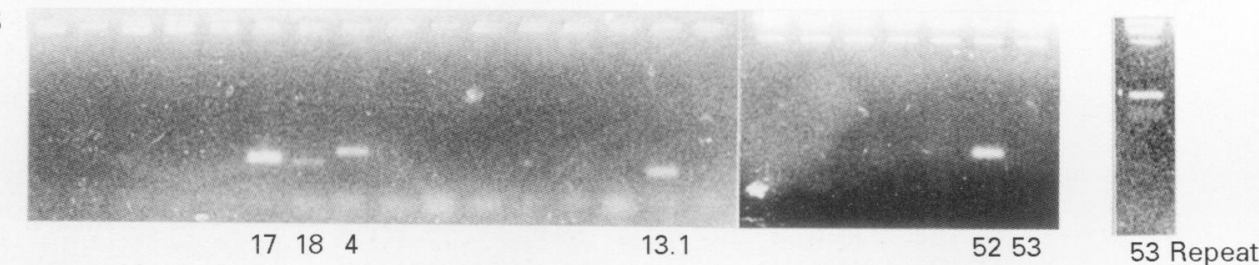

Figure $1 P C R-H L A D R B$ and $D Q B 1$ tissue typing results for case 2. (A) HLA DRB and DQB1 genotypes obtained using direct PCR-SSP analysis of DNA extracted from the decidual tissue. (B) HLA DRB genotype obtained using nested $P C R-S S P$ analysis of DNA extracted from the molar tissue. In both gels, the wells were loaded with the following HLA $D R B$ gene PCR primer mixes (from left to right): $D R B 1.1,1.2,15,16,3,17,18,4,7,8,9,10,11,12,13.1,13.2,13.3$, $14.1,14.2,14.3, D R 51$ (DRB5), DR52 (DRB3), DR53 (DRB4). Gel (A) additionally contains wells loaded with the following HLA DQB1 gene PCR mixes (from left to right): $D Q 2,4,5,6 a, 6 b, 7,8$ and 9. Gel $(A)$ shows the following positive PCR-SSP reactions: $D R B 1{ }^{\star} 04 ; D R B 4(53) ; D Q B 1{ }^{\star} 08$. Gel $(A)$ also contains visible control primer PCR product (marked) within the majority of reaction mixes. Gel (B) shows the following positive PCR-SSP reactions: $D R B 1 * 04, D R B 1 * 1302$ (positive DR 18 and DR 13.1 reaction mixes); DRB3(52). A positive DR $17\left(D R B 1{ }^{\star} 0301\right.$ ) reaction mix is also shown, although the absence of a positive adjacent broad specificity DR 3 reaction mix indicates that this is a false positive result. The DRB4(53) reaction mix failed on initial typing but produced an uneqivocal reaction product when repeated, as shown separately.

show linkage. The $\mathrm{DQB} 1^{\star} 07$ and 08 alleles detected within the molar tissue are both linked with the $\mathrm{DRB} 1{ }^{\star} 04$ allele. These results suggest that the DRB1*15 allele present within the molar tissue was derived from the maternal genome, and that the molar tissue may also contain two $\mathrm{DRB} 1^{\star} 04$ alleles, each derived from the father and linked with $\mathrm{DQB} 1{ }^{\star} 07$ and 08 , respectively. An alternative explanation is that one of the molar DRB $1^{\star} 04$ alleles was derived from the maternal genome, where it was also linked with a $\mathrm{DQB} 1^{\star} 07$ allele.

In case 7 , the molar tissue was typed as $\mathrm{DRB} 1{ }^{\star} 15,04,07 ; \mathrm{DR} 51,53 ; \mathrm{DQB} 1{ }^{\star} 02$ and the decidual tissue was typed as $\mathrm{DRB} 1^{\star} 15,04$; DR51, 53; DQB $1{ }^{\star} 06,07$. The DQB ${ }^{\star}{ }^{\star} 02$ allele identified within the molar tissue would be expected to be linked with the $\mathrm{DRB}{ }^{\star}{ }^{\star} 07$ allele and more rarely with the $\mathrm{DRB} 1^{\star} 04$ allele also observed in this tissue. ${ }^{19}$ However, no DQB1 allele that would be commonly linked with the detected DRB1*15 allele was identifiable, despite repeated typings. Nevertheless, the three DRB1 alleles detected within the molar tissue indicated triploidy within this material, and the $\mathrm{DRB} 1{ }^{\star} 15$ and $\mathrm{DRB} 1{ }^{\star} 04$ alleles were present within both the molar and maternal tissues, suggesting that at least one of these two DRB1 alleles within the molar tissue was derived from the maternal genome.

In case 8 , the decidual tissue was typed as DRB1*01，04; DR53; DQB1*05, 08. The molar tissue was untypable even using nested PCR-SSP typing.
In case 9, identical DRB1 alleles (DRB1 ${ }^{\star} 15$, 12) were detected within the molar and decidual tissue. A DQB $1^{\star} 07$ allele was identified within the molar tissue, which is commonly linked with the $\mathrm{DRB}^{\star}{ }^{\star} 12$ allele also detected in this case. No DQB1 allele was identified in either sample that would be commonly linked with the detected DRB $1{ }^{\star} 15$ allele. However, the results suggest that at least one of the DRB1 alleles within the molar tissue was derived from the maternal genome.

\section{Discussion}

In the present study we were able to identify complete HLA DRB1 genotypes in 16 of 18 DNA samples, including complete HLA DRB1 genotypes for the decidual and molar tissue from seven of nine cases of HM. In these seven cases we were also able to detect the presence of the HLA DRB3(52), -4(53), and $-5(51)$ genes. These results were obtained using a combination of direct and nested PCR-SSP typing. ${ }^{15} 21$ The sensitivity and reliability of nested PCR-SSP HLA DRB typing has already been demonstrated. ${ }^{21}$ HLA DQB1 alleles were detectable only using direct PCRSSP typing, as a reliable methodology for nested PCR-SSP typing of the DQB1 gene is still under development in our laboratory. Therefore, a complete HLA DQB1 genotype was obtainable in only five of the seven cases for which a full HLA DRB genotype was available. However, despite the extra internal control provided by linkage disequilibrium 
between the HLA DRB and DQB1 genes, a full HLA DRB genotype accompanied by a full or partial HLA DQB1 genotype provided sufficient information for meaningful conclusions to be drawn from the results of PCR-HLA class II typing in these seven cases.

The original histopathological diagnosis for the seven HM in which at least a full HLA DRB genotype was available, was complete HM in two cases (cases 1 and 2), partial HM in four cases (cases 4-7), and HM of uncertain type in one case (case 9). The HLA DRB and DQB 1 typing results obtained in cases 1 and 2 indicate a solely paternal origin for the molar genome, and strongly support the original histological diagnosis of complete HM. These HLA typing results additionally indicate that both complete HM cases must have arisen from dispermic fertilisation events. The HLA DRB and DQB1 types obtained in cases 4-7 are consistent with a partially maternal contribution to the molar genome, with at least one allele for the HLA loci studied being common to the maternal and molar tissue. The HLA DRB and DQB1 typing results in these cases provide no evidence for a solely paternally derived molar genome, and are therefore consistent with the histological diagnosis of partial HM. The HLA typing results obtained in case 9 were very similar to those observed in cases 4-7 and again provide no evidence that this HM was of purely androgenetic origin. Therefore, case 9 is not likely to be a complete HM and the results are consistent with a partial $\mathrm{HM}$. Although the majority of partial HM is believed to be triploid, ${ }^{5}$ containing two sets of chromosomes originating from the paternal genome, a third DRB1 or DQB1 allele was identified in only three of these five cases. However, the paternal HLA class II types were unknown in this study (as may also be the case in a routine diagnostic setting), and therefore paternal homozygosity for the HLA class II genes cannot be excluded.

It is possible that sharing of HLA alleles by the maternal and paternal genomes, for the HLA loci examined, may lead to HLA alleles common to the decidual and molar tissue being detected within cases of true complete HM, and incorrect assignment of these cases as partial HM. However, the combined HLA DRB and DQB1 haplotypes of the maternal and molar tissue may still differ, as in case 2 , and a diagnosis of complete HM can still be supported. Nevertheless, using current techniques, a complete HM cannot be entirely excluded if common HLA DRB and DQB1 alleles are present within molar and decidual tissue. However, the probability of this scenario could be significantly reduced through the examination of further HLA class I and class II loci, as well as the use of higher resolution HLA class II typing techniques currently under development in our laboratory.

Despite the utility of HLA class II typing as an adjunct to the histological diagnosis of HM, as evidenced by data from this study, this method still has a number of limitations compared with microsatellite analysis. For example, all HLA markers studied map to a single region of a single chromosome (6p). Therefore, finding one similar and two dissimilar polymorphisms (alleles) within molar tissue compared with decidual tissue strictly indicates trisomy for that chromosome, rather than triploidy. In contrast, microsatellite polymorphisms are present on several chromosomes and therefore define triploidy more readily. For the same reason, microsatellite polymorphisms can more accurately distinguish between monospermic and dispermic origins of complete HM, as the presence of one non-maternal allele in a complete HM could be interpreted as monospermy, but could be due to dispermy, with both sperms sharing the same HLA polymorphism. Again, these limitations could be overcome, at least in part, via examination of further HLA loci or via higher resolution HLA class II typing.

Recent studies have shown that a minority of HM with morphological features of complete HM contain genetic material originating from the maternal genome. ${ }^{28}$ These cases could not, therefore, be distinguished from partial HM using PCR HLA typing. However, the significance of a diagnosis of complete HM containing maternally derived genes appears uncertain, and must depend on whether the morphological characteristics or the genetic constitution of these HM determines their subsequent behaviour. PCR HLA typing also would not distinguish hydropic abortion from partial HM as both contain maternal and paternal genetic material. However, PCR HLA typing of cases such as maternally derived complete HM and hydropic abortion may still aid understanding of the genetic constitution of these conditions in individual patients.

We have shown that PCR-SSP HLA DRB and DQB1 typing can act as a valuable adjunct to histological examination for the distinction of complete from partial HM. This technique may be of practical use in laboratories with an established HLA DNA typing facility, even though a large number of PCR reactions must be performed to establish a DRB and DQB type. Because of the varied genetic constitution of both complete and partial HM, no single test based on identification of particular genetic characteristics of HM can provide an unequivocal solution to this problem in all cases. However, PCR-based detection of HLA alleles within molar tissue that are entirely different from those identified within the corresponding maternal decidual tissue strongly supports a diagnosis of complete HM. Identification of individually interpretable HLA class II genotypes within each DNA sample, and the genetic linkage present between the HLA DRB1, -3, $-4,-5$, and DQB1 genes, provides internal controls and an ability to estimate both genetic ploidy and the mode of origin of complete HM (that is, dispermy versus monospermy). The successful application of this technique to the potentially limited quantities of intact DNA extractable from formalin fixed and paraffin wax embedded tissue allows routine paraffin biopsy material, including archival cases, to be used as a source of DNA for this method. 
This work was supported in part by a grant from the Wessex Cancer Trust.

1 Bracken MB. Incidence and aetiology of hydatidiform mole: an epidemiological review. $\mathrm{Br} \mathcal{F}$ Obstet Gynaecol an epidemiological

2 Fukunaga $M$, Ushigome S, Fukunaga $M$, Sugishita $M$ Application of flow cytometry in diagnosis of hydatidiform mole. Modern Pathol 1993;6:353-9.

3 Paradinas FJ, Browne P, Fisher RA, Foskett M, Bagshawe $\mathrm{KD}$, Newlands E. A clinical, histopathological and flow cytometric study of 149 complete moles, 146 partial moles and 107 non-molar hydropic abortions. Histopathology 1996;28:101-9.

4 Kajii T, Ohama K. Androgenetic origin of hydatidiform mole. Nature 1977;268:633-4.

5 Jacobs PA, Szulman AE, Funkhouser J, Matsuura JS, Wilson CC. Human triploidy: relationship between parental origin of the additional haploid component and development of partial hydatidiform mole. Ann Hum Genet 1982;46:22331 .

6 Yabe N, Maeda T, Kashiwagi N, Obata F. Genetic analysis of hydatidiform moles utilizing the oligonucleotide-DNA typing of the HLA-DRB gene. Placenta 1994;15:541-9.

7 Tóth A, Arató G, Szepesi J, Hajdu K, Szigetvári I, László J. Tetraploidy in human placenta: a dilemma in molar and non-molar pregnancies. Gynecol Obstet Invest 1992;33:1536.

8 Bocklage TJ, Smith HO, Bartow SA. Distinctive flow histogram pattern in molar pregnancies with elevated maternal serum human chorionic gonadotropin levels. Cancer 1994; 73:2782-90.

9 Takahashi $H$, Ikarashi $T$, Kanazawa $K$, Kominami $R$ Tanaka K. Re-evaluation of hydatidiform mole by DNA fingerprint method: the discrepancy in the diagnoses by fingerprint method: the discrepancy in the diagnoses by
pathological finding and the fingerprint method. Placenta pathological finding

10 Arima $T$, Imamura $T$, Amada $S$, Tsuneyoshi $M$, Wake N. Genetic origin of malignant trophoblastic neoplasms. Cancer Genet Cytogenet 1994;73:95-102.

11 Lane SA, Taylor GR, Ozols B, Quirke P. Diagnosis of complete molar pregnancy by microsatellites in archival material. $\mathcal{F}$ Clin Pathol 1993;46:346-8.

12 Fukuyama R, Takata M, Kudoh J, Sakai K, Tamura S, Shimizu N. DNA diagnosis of hydatidiform mole using the polymerase chain reaction. Hum Genet 1991;87:216-18.

13 Fisher RA, Newlands ES. Rapid diagnosis and classification Fisher RA, Newlands ES. Rapid diagnosis and classification of hydatidiform moles with polym
$\mathcal{F}$ Obstet Gynecol 1993;168:563-9.

14 Bateman AC, Leung ST, Howell WM, Roche WR, Jones DB, Theaker JM. Detection of specimen contamination in routine histopathology by HLA class II typing using the polymerase chain reaction and sequence specific oligonucleotide probing. $\mathcal{F}$ Pathol 1994;173:243-8.

15 Bateman AC, Sage DA, Al-Talib RK, Theaker JM, Jones $\mathrm{DB}$, Howell WM. Investigation of specimen mislabelling in paraffin-embedded tissue using a rapid, allele-specific PCR-based HLA class II typing method. Histopathology 1996;28:169-74.

16 Fernandez-Vina MA, Tiercy J-M, Tonai R, KatovichHurley C, Tsai J, Stastny P. DNA typing of DRB1 and DR3 DR52-related specificities. In: Tsuji K, Aizawa M, Sasazuki T, eds. HLA 1991, Vol 1. Oxford: Oxford University Press, 1992:471-7.

17 Giphart MJ, D'Amaro J, Drabbels J, Schipper R, Taneja V, Mehra NK, et al. Analysis of HLA-DR1 and -DR2 alleles. In: Tsuji K, Aizawa M, Sasazuki T, eds. HLA 1991, Vol 1. Oxford: Oxford University Press, 1992:457-65.

18 Imanishi T, Akaza T, Kimura A, Tokunaga T, Gojobori T. Allele and haplotype frequencies for HLA and complement loci in various ethnic groups. In: Tsuji $\mathrm{K}$, Aizawa $\mathrm{M}$, Sasazuki T, eds. HLA 1991, Vol 1. Oxford: Oxford University Press, 1992:1065-220.

19 Stastny P, Kimura A. DNA typing analysis of the DR4 group. In: Tsuji K, Aizawa M, Sasazuki T, eds. HLA 1991, Vol 1. Oxford: Oxford University Press, 1992:465-70.

20 Howell WM, Leung ST, Jones DB, Nakshabendi I, Hall MA, Lanchborg JS, et al. HLA-DRB, -DQA, and -DQB polymorphism in celiac disease and enteropathy-associated T-cell lymphoma. Common features and additional risk factors for malignancy. Human Immunol 1995;43:29-37.

21 Bateman AC, Hemmatpour SK, Theaker JM, Howell WM. Nested polymerase chain reaction-based HLA class II typing for the unique identification of formalin-fixed and paraffin-embedded tissue. F Pathol 1977;181:228-34.

22 Olerup O, Zetterquist H. HLA-DR typing by PCR amplification with sequence-specific primers (PCR-SSP) in 2 to serological DR typing in clini practice including donor-recipient matching in cadaveric practice including donor-recipient matching in

23 Olerup O, Zetterquist H. DR "low resolution" PCR-SSP typing-a correction and an update. Tissue Antigen 1993;40:55-6.

24 Bunce M, Taylor CJ, Welsh KI. Rapid HLA-DQB typing by eight polymerase chain reaction amplifications with sequence specific primers (PCR-SSP). Hum Immunol 1993;37:201-6.

25 Marsh SGE, Bodmer JG. HLA class II region nucleotide sequences, 1995. Tissue Antigens 1995;45:258-80.

26 Aldener-Cannavá A, Olerup O. HLA-DQB1 "low resolution" typing by PCR amplification with sequence specific primers (PCR-SSP). Eur 7 Immunogenet 1994;21:447-55.

27 Kimura A, Sasazuki T. Eleventh International Histocompatibility Workshop reference protocol for the HLA DNAtyping technique. In: Tsuji $\mathrm{K}$, Aizawa $\mathrm{M}$, Sasazuki T, eds. typing technique. In: Tsuji K, Aizawa M, Sasazuki T, eds. 1992:397-439.

28 Kovacs BW, Shahbahrami B, Tast DE, Curtin JP. Molecular genetic analysis of complete hydatidiform moles. Cancer Genet Cytogenet 1991;54:143-52. 